\title{
Experimental Study of a Pack of Supercapacitors Used in Electric Vehicles
}

\author{
Amari Mansour, ${ }^{1}$ Chabchoub Mohamed Hedi, ${ }^{2}$ and Bacha Faouzi ${ }^{1}$ \\ ${ }^{1}$ Laboratory of Computer Science for Industrial Systems, INSAT, Tunis, Tunisia \\ ${ }^{2}$ Computer Embedded System (CES) Laboratory, National School of Engineers of Sfax (ENIS), Sfax, Tunisia
}

Correspondence should be addressed to Amari Mansour; mansour.amari@gmail.com

Received 4 May 2017; Accepted 11 July 2017; Published 14 August 2017

Academic Editor: Rizwan Raza

Copyright (C) 2017 Amari Mansour et al. This is an open access article distributed under the Creative Commons Attribution License, which permits unrestricted use, distribution, and reproduction in any medium, provided the original work is properly cited.

Electric vehicles have recently attracted research interest. An electric vehicle is composed of two energy sources, such as fuel cells and ultracapacitors, which are employed to provide, respectively, the steady-state and transient power demanded by the vehicle. A bidirectional DC-DC converter is needed to interface the ultracapacitor to a DC bus. The pack of ultracapacitor consists of many cells in series and possibly also in parallel. In this regard, this paper introduces a comparative study between two packs of supercapacitors. The first supercapacitor pack is composed of ten cells in series but the second supercapacitor pack is composed of five cells in series and two parallel circuits. Each cell is characterized by $2.5 \mathrm{~V}$ and $100 \mathrm{~F}$. A number of practical tests are presented.

\section{Introduction}

Rapidly increasing population, energy consumption, and the need to reduce emissions through the conventional vehicle have motivated researchers to study the electric hybrid vehicles (EHVs) [1]. Usually, the electric hybrid vehicles architecture includes two or more energy sources with their associated energy converters as shown in Figure 1.

The main source is a fuel cell, with high energy storage capability; it is the electrochemical devices that convert chemical energy of a reaction directly into electrical energy [2]. This has slow dynamic to response under load variation and does not allow the recuperation of energy from the load [3]. The second source is the storage system; it produces the lacking power in acceleration and absorbs excess power in braking function. Batteries and ultracapacitors are employed as energy storage system in many hybrid applications. Recently, ultracapacitors have been explored better than batteries in the electrical vehicles because they present considerably higher power densities than those of batteries, and extremely higher energy densities than those of conventional electrolytic capacitors $[4,5]$. The graph in Figure 2 illustrates the regions of applicability of the various energy storage systems [6].

Other than electric vehicles, supercapacitor can also be used as additional energy storage for hybrid wind and photovoltaic system. It charges energy when it is windy or sunny and discharges when there is no power generated from photovoltaic or wind due to the sudden passing clouds disturbance or very low wind speed [7]. Hence, it is necessary to understand the characteristics of the supercapacitor and determine these different electric models. In the literature many models have been developed such as electrochemical models and equivalent circuit ones. This paper presents a practical comparative study of equivalent circuit models of ultracapacitors used in electric vehicles. This paper is summarized as follows. Section 2 describes the ultracapacitor model. Section 3 details the topology of the boost, the operation mode, and the average model. Section 4 evaluates the simulation and the experimental results. And finally the conclusion is presented in Section 5 .

\section{Ultracapacitor Modeling}

Ultracapacitors consist of two electrodes and an ionpermeable separator that prevents physical contact between the two electrodes [8]. They are characterized by high power density, high energy efficiency, low internal resistance, long cycle life, and fast charging/discharging time. In recent years as ultracapacitors become used more widely, several different circuit models have been proposed in the literature [9]. 


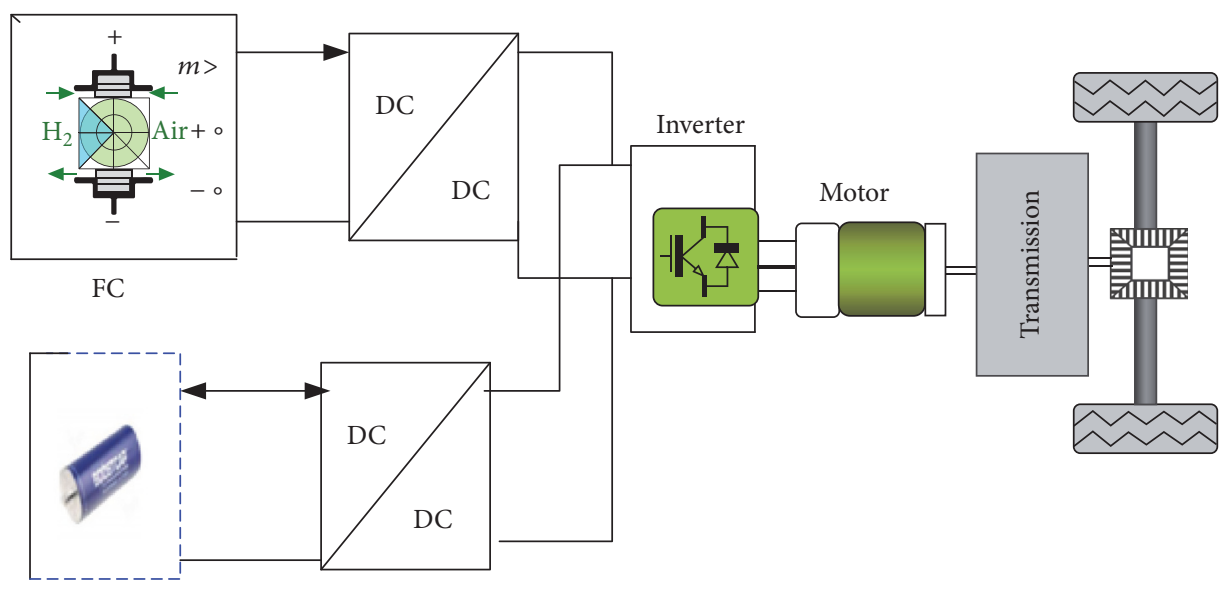

FIGURE 1: Electric vehicle system.

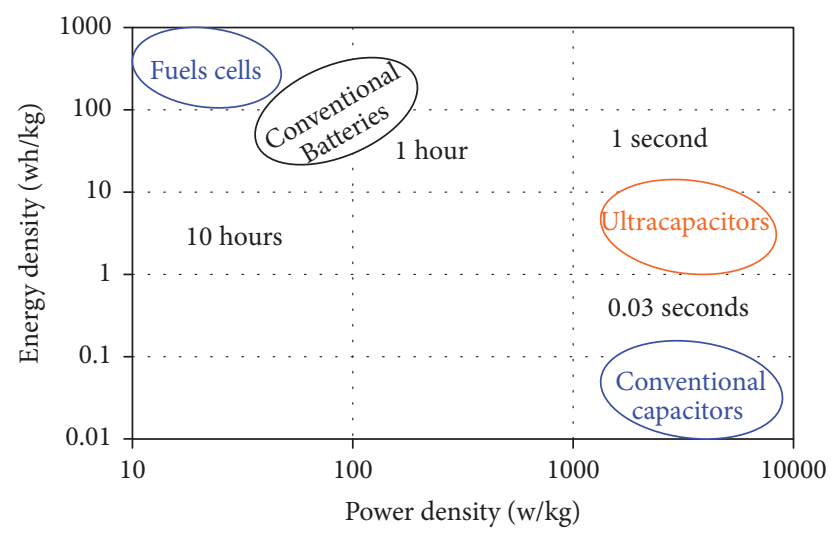

FIGURE 2: Ragone diagram of energy storage sources.

2.1. RC Circuit Model. The circuit schematic in Figure 3 represents the simple $\mathrm{RC}$ model for a ultracapacitor. It is comprised of three ideal circuit elements: a series resistor $R_{s}$ : it is called the equivalent series resistor (ESR) and contributes to the energy loss component of the ultracapacitor during charging or discharging; a parallel resistor $R_{p}$ : it is called the leakage resistance, and a capacitance $C_{\mathrm{sc}}$. This model is developed and validated experimentally in many works $[5,10-12]$.

The dynamic can be described as

$$
\begin{gathered}
\frac{d u_{1}(t)}{d t}=\frac{-u_{1}(t)}{R_{p} C_{\mathrm{sc}}}+\frac{I_{\mathrm{sc}}}{C_{\mathrm{sc}}} \\
V_{\mathrm{sc}}(t)=R_{s} I_{\mathrm{sc}}+u_{1}(t) .
\end{gathered}
$$

The ultracapacitor is discharged with a constant current and the result is presented in Figure 4.

The equivalent series resistor is obtained through the following equation:

$$
R_{s}=\frac{\Delta U}{I_{\text {dech }}},
$$

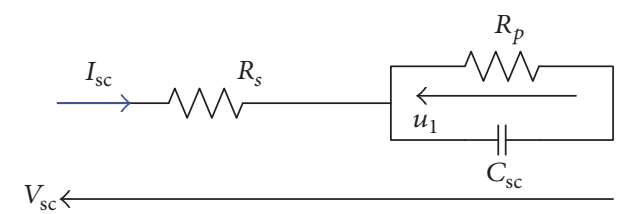

Figure 3: Classical model.

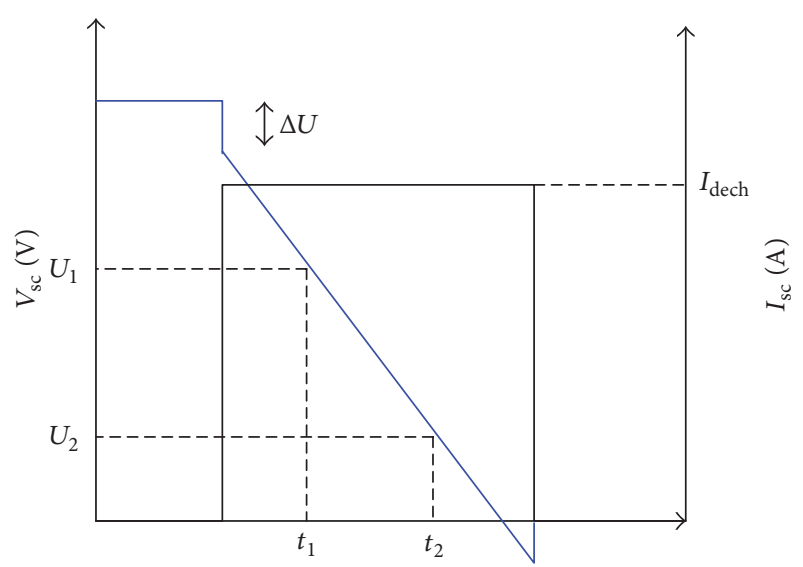

FIGURE 4: Evolution of voltage discharged with a constant current.

where $\Delta U$ and $I_{\text {dech }}$ denote, respectively, the voltage drop which is observed at the beginning of the discharge and the discharge current.

The capacitor can be expressed by

$$
C_{\mathrm{sc}}=\frac{I_{\mathrm{dech}}\left(t_{2}-t_{1}\right)}{U_{1}-U_{2}} .
$$

The parallel resistor is calculated using

$$
R_{p}=\frac{U_{1}}{I_{L}}
$$

where $U_{1}$ and $I_{L}$ denote, respectively, the open circuit voltage and the leakage current. 


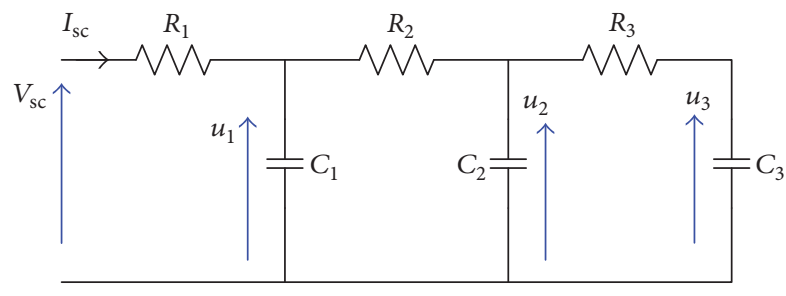

FIGURE 5: Three-stage ladder model.

2.2. Three-Stage Ladder Model. The three-stage ladder model is shown in Figure 5. It is composed of three resistors and three capacitors. This model is developed in many references [13-15].

To model the three-stage ladder model we choose three state variables including capacitors voltages $u_{1}, u_{2}$, and $u_{3}$. The state space representation is described by the following equation:

$$
\begin{array}{r}
\frac{d x}{d t}=A x+B u \\
y=C x+D u,
\end{array}
$$

where $x=\left[\begin{array}{lll}u_{1} & u_{2} & u_{3}\end{array}\right]^{T}, u=I_{\mathrm{sc}}$, and $y=V_{\mathrm{sc}}$.

According to basic electrical circuit principles, the matrix expressions are the following:

$$
\begin{aligned}
A & =\left[\begin{array}{ccc}
\frac{-1}{R_{2} C_{1}} & \frac{1}{R_{2} C_{1}} & 0 \\
\frac{-1}{R_{2} C_{2}} & \frac{-\left(R_{2}+R_{3}\right)}{R_{2} R_{3} C_{2}} & \frac{1}{R_{3} C_{2}} \\
0 & \frac{1}{R_{3} C_{3}} & \frac{-1}{R_{3} C_{3}}
\end{array}\right] ; \\
B & =\left[\begin{array}{lll}
\frac{1}{C_{1}} & 0 & 0
\end{array}\right]^{T}, \\
C & =\left[\begin{array}{lll}
1 & 0 & 0
\end{array}\right], \\
D & =\left[\begin{array}{lll}
R_{\mathrm{sc}}
\end{array}\right] .
\end{aligned}
$$

2.3. The Dynamic Model. In this case, the equivalent circuit is composed of two parallel circuit RC. It has the structure shown in Figure 6 where $u_{0}$ denotes the voltage across the bulk capacitor $C_{\mathrm{sc}}, u_{1}$ and $u_{2}$ denote the voltages of the two RC circuits, respectively, $V_{\mathrm{sc}}$ denotes the output voltage, and $R_{\mathrm{sc}}$ denotes the series resistance [16].

The state space representation can be derived as

$$
\begin{aligned}
{\left[\begin{array}{l}
\frac{d u_{0}}{d t} \\
\frac{d u_{1}}{d t} \\
\frac{d u_{2}}{d t}
\end{array}\right]=\left[\begin{array}{ccc}
0 & 0 & 0 \\
0 & \frac{-R_{1}}{C_{1}} & 0 \\
0 & 0 & \frac{-R_{2}}{C_{2}}
\end{array}\right]\left[\begin{array}{l}
u_{0} \\
u_{1} \\
u_{2}
\end{array}\right]+\left[\begin{array}{c}
\frac{1}{C_{s c}} \\
\frac{1}{C_{1}} \\
\frac{1}{C_{2}}
\end{array}\right] I_{\mathrm{sc}} } \\
V_{\mathrm{sc}}=u_{0}+u_{1}+u_{2}+R_{\mathrm{sc}} I_{\mathrm{sc}} .
\end{aligned}
$$

TABLE 1: State of the switches.

\begin{tabular}{lcc}
\hline Switch & Charging mode & Discharging mode \\
\hline$T_{1}$ & 0 & {$\left[\begin{array}{ll}0 & d_{1} T_{s}\end{array}\right]$} \\
$T_{2}$ & {$\left[\begin{array}{lll}0 & d_{2} T_{s}\end{array}\right]$} & 0 \\
$D_{1}$ & 0 & {$\left[\begin{array}{cc}0 & d_{1} T_{s}\end{array}\right]$} \\
$D_{2}$ & {$\left[\begin{array}{ll}d_{2} T_{s} & T_{s}\end{array}\right]$} & 0 \\
\hline
\end{tabular}

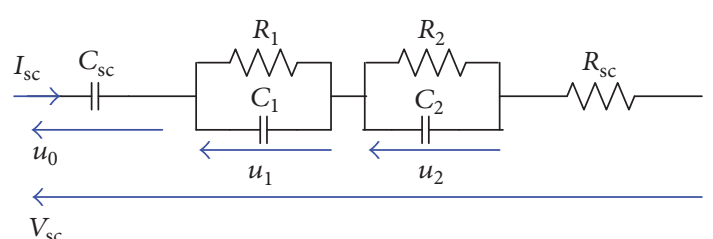

Figure 6: The dynamic model.

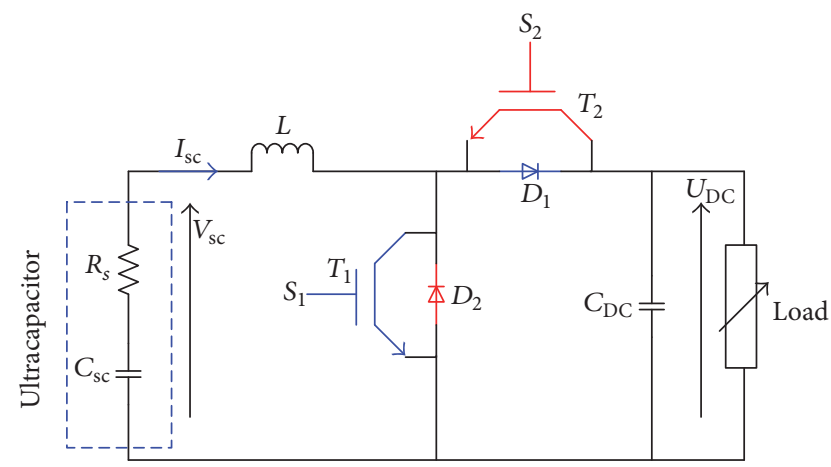

FIGURE 7: Topology of DC-DC converter.

\section{Topology of Converter}

There are many possible topologies of DC-DC converters which interface the ultracapacitor and the DC link. The DCDC converters can be divided into two categories depending on using the galvanic insulation or not: nonisolated converter or isolated converter. The proposed converter has two basic operating modes: the buck and the boost mode. In this context, many papers have been elaborated [17-19]. Figure 7 shows the converter topology. The chosen DC-DC converter is composed of two IGBTs, two diodes, inductor, and capacitor.

There are two modes. (a) Charging mode: in this case, the load delivers the energy to the capacitor through the IGBT $\left(T_{2}\right)$, the diode $\left(D_{2}\right)$, and the inductor $L$. (b) Discharging mode: in this case, the ultracapacitor delivers the energy to the load through the IGBT $\left(T_{1}\right)$, the diode $D_{1}$, and the inductor $L$. Table 1 shows the state of any switch for two modes, where $T_{s}, d_{1}$, and $d_{2}$ denote, respectively, the switching period, the duty cycle in charging mode, and the duty cycle in discharging mode.

The key factors that determine the parameters of the circuit include the limit ripple of the ultracapacitor current $\left(\delta\left(I_{\mathrm{sc}}\right)\right)$ and the ripple of the output voltage $\left(\delta\left(V_{\mathrm{DC}}\right)\right)$, the switching period $\left(T_{s}\right)$, and the output power $\left(P_{\text {out }}\right)$. In 


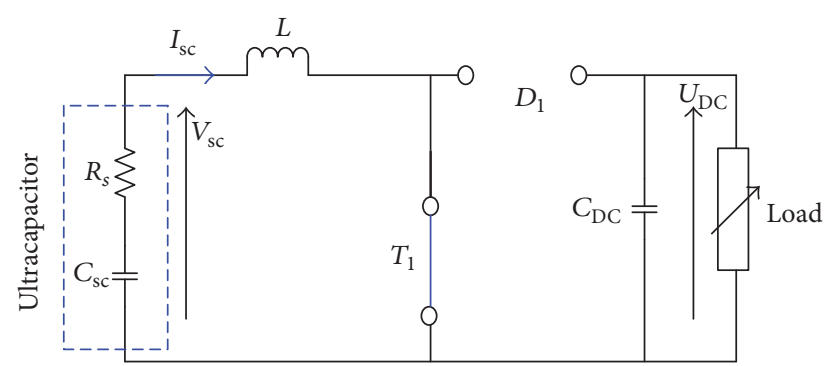

FIgURE 8: Equivalent circuit for Case 1.

discharging mode the inductor and the output capacitor are described by the following equation:

$$
\begin{aligned}
& L \geq \frac{V_{\mathrm{sc}} d_{2} T_{s}}{I_{\mathrm{sc}} \delta\left(I_{\mathrm{sc}}\right)} \\
& C \geq \frac{d_{2}\left(1-d_{2}\right)^{2} T_{s} I_{\mathrm{sc}}}{V_{\mathrm{sc}} \delta\left(V_{\mathrm{DC}}\right)} .
\end{aligned}
$$

In this application, the ultracapacitor voltage is $25 \mathrm{~V}$, if we choose $I_{\mathrm{sc}}=4 \mathrm{~A}, V_{\mathrm{DC}}=125 \mathrm{~V}, T_{s}=5 e^{-4} \mathrm{~s}$, and $\delta\left(I_{\mathrm{sc}}\right)=$ $\delta\left(V_{\mathrm{DC}}\right)=5 \%$. The boost parameters are $d_{1}=0.8, L=50 \mathrm{mH}$, and $C=256 \mu \mathrm{F}$.

To model the boost converter, we used the average method. In this case, it is assumed that all components are ideal; that is, there is no internal resistance in the circuit and the circuit components do not consume any energy. We choose two state variables including output voltage and inductor current. The system state space representation is

$$
\begin{aligned}
& x=A x+B \cdot u \\
& y=C \cdot x,
\end{aligned}
$$

where $u$ is the vector of inputs, $y$ is the outputs, and $x$ is the status variables vector.

$$
\begin{aligned}
x & =\left[i_{\mathrm{sc}}(t), v_{\mathrm{DC}}(t)\right]^{T}, \\
y(t) & =v_{\mathrm{DC}}(t), \\
u(t) & =v_{\mathrm{sc}}(t) .
\end{aligned}
$$

During the switching period, the topology converter can be divided into two equivalent circuits.

Case $1\left(t \in\left[\begin{array}{ll}0 & d_{1} T_{s}\end{array}\right]\right)$. The switch $T_{1}$ is $\mathrm{ON}$; the equivalent circuit can be simplified as shown Figure 8.

We can write the state space by the following equation:

$$
\begin{aligned}
& x=A_{1} x+B_{1} \cdot u \\
& y=C_{1} \cdot x .
\end{aligned}
$$

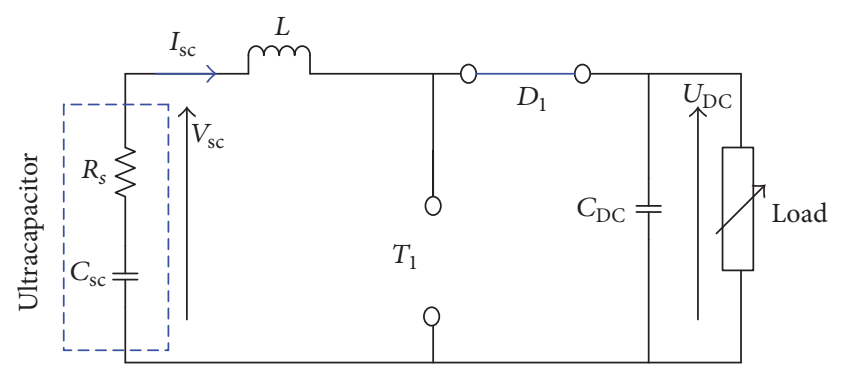

Figure 9: Equivalent circuit for Case 2.

The matrices $A_{1}, B_{1}$, and $C_{1}$ can be expressed as follows:

$$
\begin{aligned}
& A_{1}=\left[\begin{array}{cc}
0 & 0 \\
0 & \frac{-1}{R_{\mathrm{Load}} C_{\mathrm{DC}}}
\end{array}\right], \\
& B_{1}=\left[\begin{array}{c}
\frac{1}{L} \\
0
\end{array}\right], \\
& C_{1}=\left[\begin{array}{ll}
0 & 1
\end{array}\right] .
\end{aligned}
$$

Case $2\left(t \in\left[\begin{array}{ll}d_{1} T_{s} & T_{s}\end{array}\right]\right)$. In this case, the switch $T_{1}$ is OFF; the ultracapacitor delivers the energy to the load through the inductor and the diode $D_{1}$. The equivalent circuit can be simplified as shown in Figure 9.

Using Kirchhoff law, the state space model is the following:

$$
\begin{aligned}
& x=A_{2} x+B_{2} \cdot u \\
& y=C_{2} \cdot x .
\end{aligned}
$$

The matrices $A_{2}, B_{2}$, and $C_{2}$ can be expressed as follows:

$$
\begin{aligned}
A_{2} & =\left[\begin{array}{cc}
0 & 0 \\
\frac{1}{C_{\mathrm{DC}}} & \frac{-1}{R_{\mathrm{Load}} C_{\mathrm{DC}}}
\end{array}\right], \\
B_{2} & =\left[\begin{array}{c}
\frac{1}{L} \\
0
\end{array}\right], \\
C_{2} & =\left[\begin{array}{ll}
0 & 1
\end{array}\right] .
\end{aligned}
$$

The average state model is

$$
\begin{aligned}
& x=A x+B \cdot u \\
& y=C \cdot x,
\end{aligned}
$$

where

$$
\begin{aligned}
& A=d_{1} \cdot A_{1}+\left(1-d_{1}\right) A_{2} \\
& B=d_{1} B_{1}+\left(1-d_{1}\right) B_{2} \\
& C=d_{1} C_{1}+\left(1-d_{1}\right) C_{2} .
\end{aligned}
$$




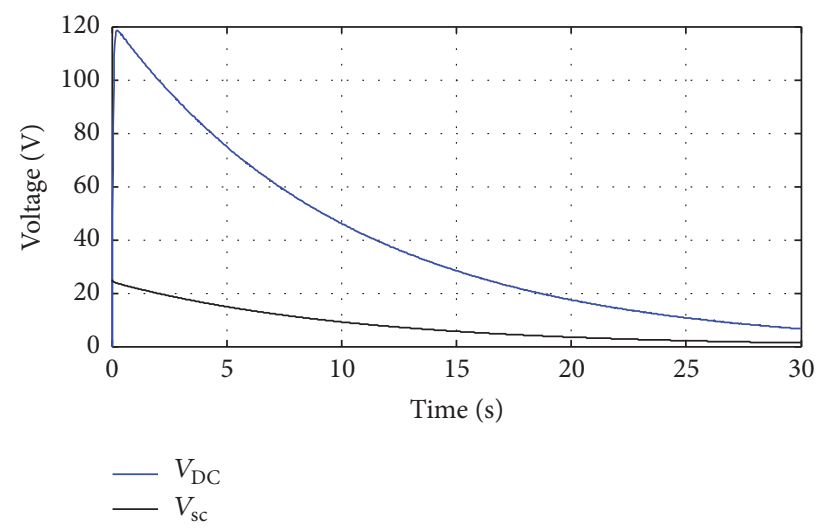

FIgURE 10: Output and the ultracapacitor voltage.

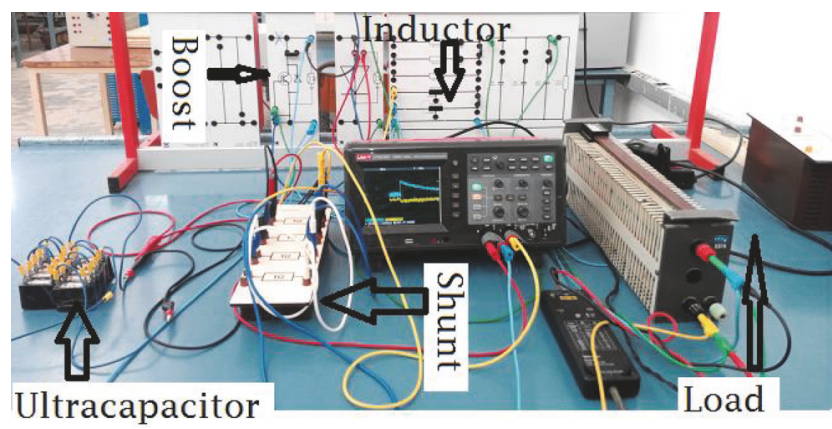

FIGURE 11: Test circuit.

If we insert (12) and (14) in (16), the matrices $A, B$, and $C$ are

$$
\begin{aligned}
& A=\left[\begin{array}{cc}
0 & \frac{d_{1}-1}{L} \\
\frac{1-d_{1}}{C_{\mathrm{DC}}} & \frac{-1}{R_{\mathrm{Load}} C_{\mathrm{DC}}}
\end{array}\right], \\
& B=\left[\begin{array}{c}
\frac{1}{L} \\
0
\end{array}\right], \\
& C=\left[\begin{array}{ll}
0 & 1
\end{array}\right] .
\end{aligned}
$$

In MATLAB, we simulate the open loop response to verify the average model using the circuit parameter defined by (8). We initialize the system by choosing the duty cycle at 0.8 and the load resistor at $25 \Omega$. Figure 10 illustrates the DC link and the ultracapacitor voltage.

\section{Experimental Validations}

A test system has been developed allowing the supercapacitor to be charged and discharged and to calculate the equivalent circuit parameters. The test circuit shown in Figure 11 allows delivering a range of voltages and currents (charge and discharge mode) and hence is capable of characterizing the range of supercapacitors used in this application. The prototype consists of ten cells (maximum stack voltage of $25 \mathrm{~V}$ ), a boost converter (IGBT module, diode, and inductor), and a load.
TABLE 2: Ultracapacitor specifications.

\begin{tabular}{lc}
\hline Parameter & Value \\
\hline Voltage cell & $V_{\mathrm{sc}}=2.5 \mathrm{~V}$ \\
Capacitor cell & $C_{\mathrm{sc}}=100 \mathrm{~F}$ \\
Resistor & $\operatorname{Resr}=36 \mathrm{~m} \Omega$ \\
Cell number & 10 \\
\hline
\end{tabular}

TABLE 3: Voltage cells value.

\begin{tabular}{lc}
\hline Number of cells & Cell voltage $(\mathrm{V})$ \\
\hline 1 & 2.603 \\
2 & 2.609 \\
3 & 2.3 \\
4 & 2.571 \\
5 & 2.589 \\
6 & 2.538 \\
7 & 2.482 \\
8 & 2.484 \\
9 & 2.512 \\
10 & 2.451 \\
\hline
\end{tabular}

The used ultracapacitor is Wima (made in Germany). These specifications are given in Table 2.

Two experiments are carried out using this setup. In the first experiment, the ten cells are connected in series, while the second one demonstrates the functionality of the system when the supercapacitors are connected in two parallel circuits.

\subsection{Charging Mode}

4.1.1. Case 1. In this case the ultracapacitors are connected in series and are charging with constant current (4.25 A). Figure 12 shows the current, voltage, and power waveforms of the ultracapacitor.

Figure 12 shows that the charging time of the supercapacitor is equal to 66 seconds. In this case, the equivalent capacitor of the ultracapacitor module is $10.8 \mathrm{~F}$. The cell capacitor and the equivalent series resistor are equal, respectively, to $108 \mathrm{~F}$ and $36 \mathrm{~m} \Omega$.

The voltage cells obtained from this condition are summarized in Table 3.

According to this table, the voltages of the different cells are not identical; that is why it is important to use a voltage balancing circuit.

4.1.2. Case 2. In this case, the ten cells of this module are divided into two parallel circuits and charged with constant current as shown in Figure 13. The charging time is equal to $140 \mathrm{~s}$.

4.2. Discharging Mode. Initially, the supercapacitor pack is fully charged. It provides power to the load through the IGBT, smoothing inductance, and diode. The control circuit allows varying the duty cycle and the switching frequency.

4.2.1. Case 1: The Ultracapacitors Cells Are Connected in Series. The experimental results in discharging mode are obtained with (0.8 and 0.6$)$ as the duty cycle and loads $(25 \Omega)$. Figure 14 

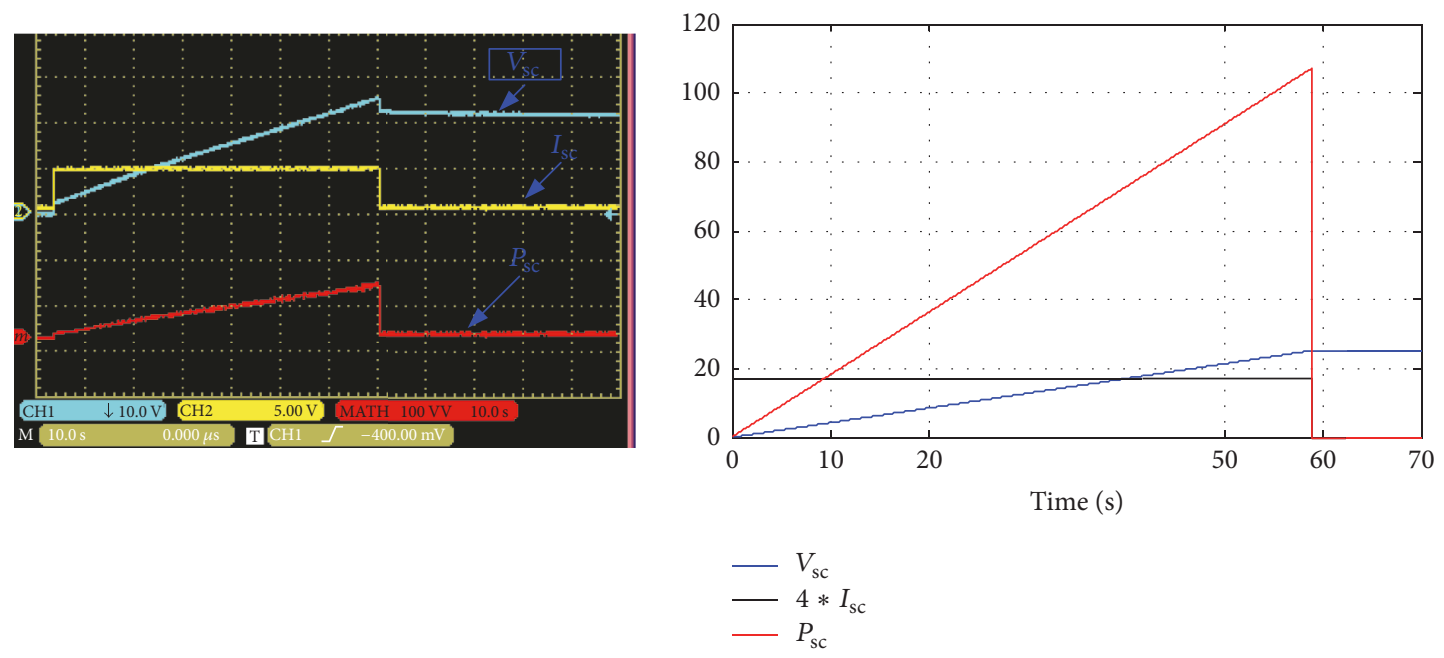

FIGURE 12: Voltage, current, and power waveforms of the ultracapacitors (charging mode-series).

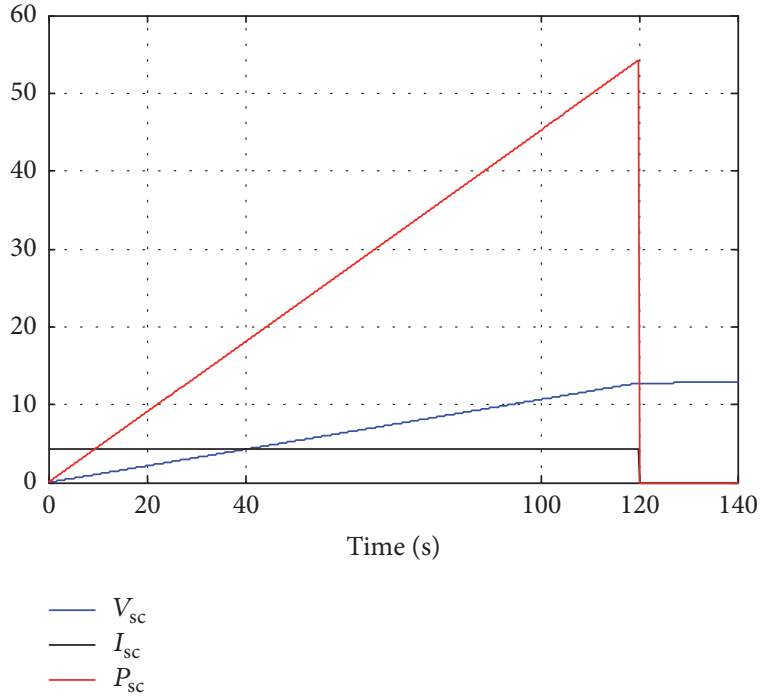

(a) Simulation

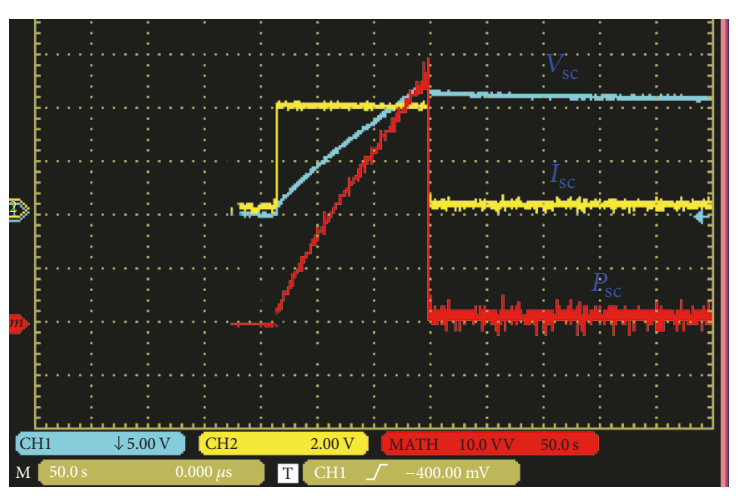

(b) Experimental

FIGURE 13: Voltage, current, and power waveforms of the ultracapacitors (charging mode-parallel).

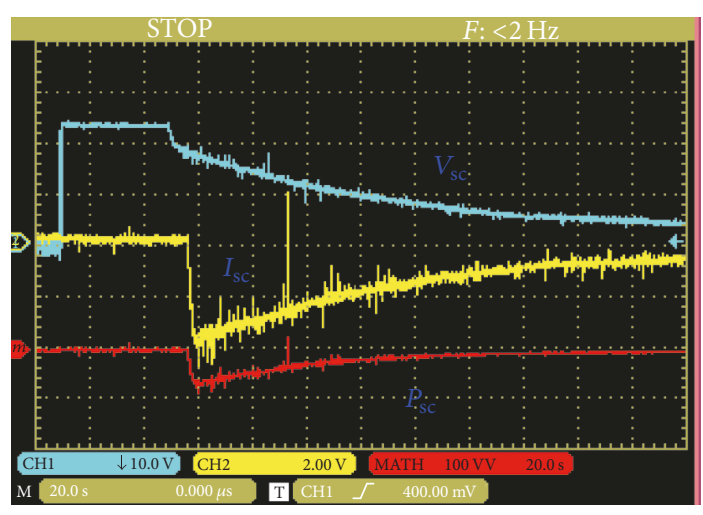

(a) Duty cycle $=0.8$

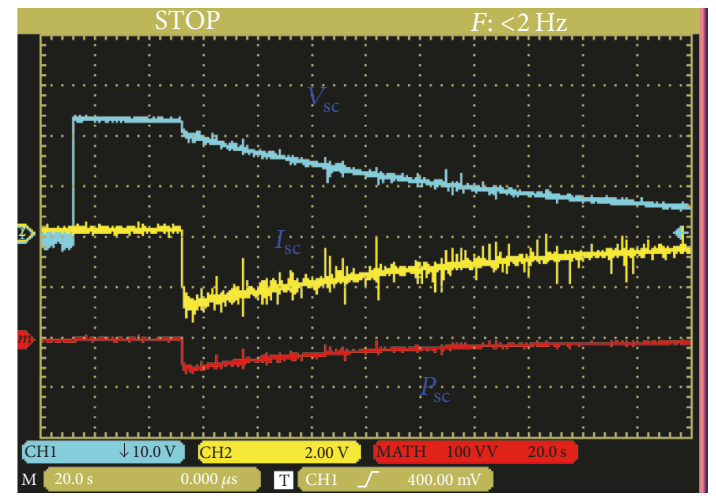

(b) Duty cycle $=0.6$

FIGURE 14: Voltage, current, and power waveforms of the ultracapacitors (discharging mode: series). 


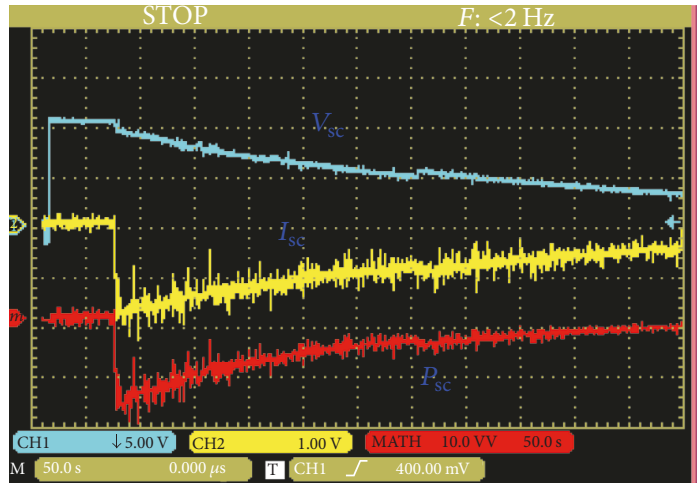

(a) Duty cycle $=0.8$

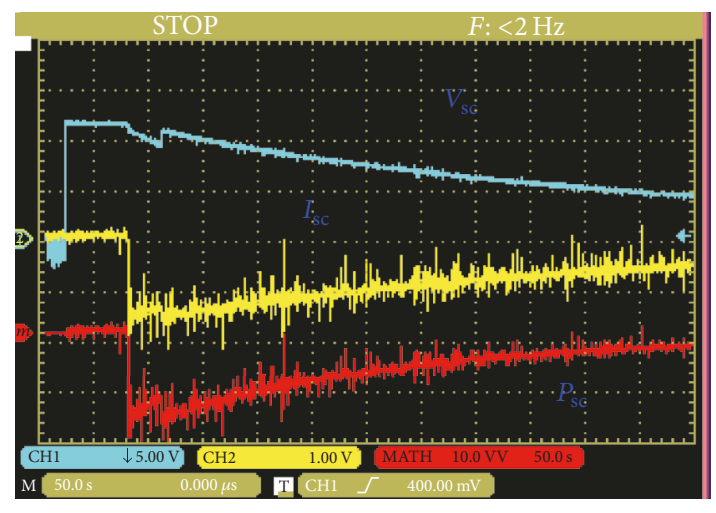

(b) Duty cycle $=0.6$

FIGURE 15: Voltage, current, and power waveforms of the ultracapacitors (discharging mode: parallel).

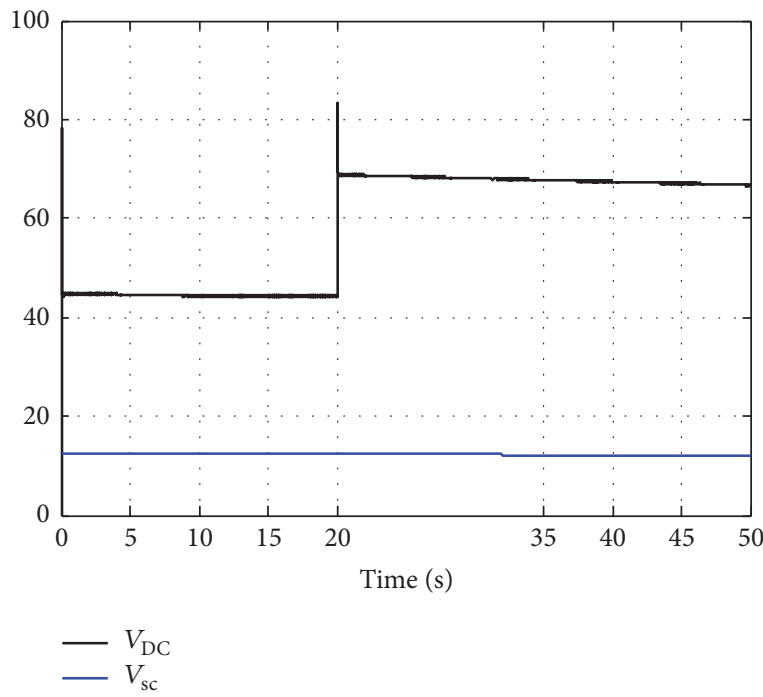

(a) Simulation

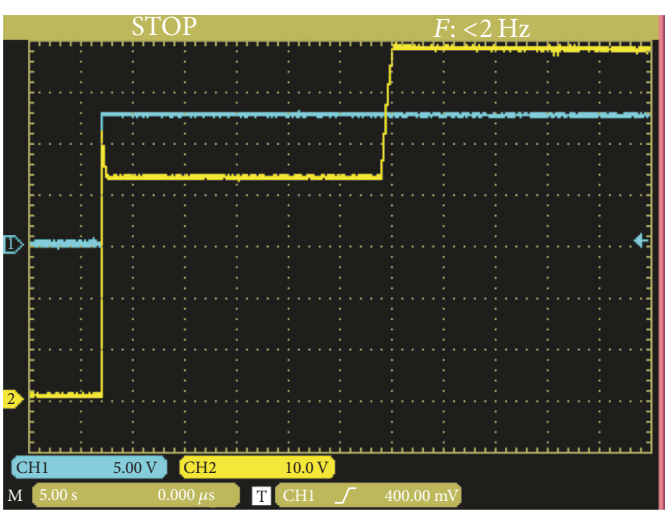

(b) Experimental

FIGURE 16: Simulation and experimental results for step change of the duty cycle.

presents the voltage, current, and power of ultracapacitors for two- duty cycle.

\subsubsection{Case 2: The Ultracapacitors Cells Are Connected into} Two Parallel Circuits. In this case, the ten cells of this module are divided into two parallel circuits and deliver the energy to the load through the boost and the inductor. Figure 15 shows the voltage, current, and power for two values of duty cycle (0.8 and 0.6$)$.

In this case the current system and average model are simulated with $d_{1}=0.72$ and then in time of 20 seconds the duty cycle changes from 0.72 to 0.82 . Figure 16 shows the simulation and the experimental results.

\section{Conclusion}

An ultracapacitor bank has been simulated and tested. The system uses a IGBT boost converter; the control of the system measures the ultracapacitor voltage, the ultracapacitor current, and the output voltage. A simple experimental methodology is proposed for a systematic validation of average models in time domain and tested the ultracapacitor performance for two connections (series and parallel). We have assumed a purely resistive load, which is not always the case in practice (acceleration and regenerative braking for an electric vehicle). It can be interesting to study the system (buck-boost + ultracapacitor) associated with an electric machine.

\section{Conflicts of Interest}

The authors declare that they have no conflicts of interest.

\section{References}

[1] Y. Ates, O. Erdinc, M. Uzunoglu, and B. Vural, "Energy management of an FC/UC hybrid vehicular power system using a combined neural network-wavelet transform based strategy," 
International Journal of Hydrogen Energy, vol. 35, no. 2, pp. 774783, 2010.

[2] H. Marzougui, M. Amari, A. Kadri, F. Bacha, and J. Ghouili, "Energy management of fuel cell/battery/ultracapacitor in electrical hybrid vehicle," International Journal of Hydrogen Energy, vol. 42, no. 13, pp. 8857-8869, 2016.

[3] M. Amari, F. Bacha, and J. Ghouili, "Average model of dual active bridge interfacing ultra-capacitor used in electrical vehicle," International Journal of Energy Optimization and Engineering, vol. 4, pp. 36-54, 2015.

[4] A. Payman, S. Pierfederici, and F. Meibody-Tabar, "Energy control of supercapacitor/fuel cell hybrid power source," Energy Conversion and Management, vol. 49, no. 6, pp. 1637-1644, 2008.

[5] L. Zhang, Z. Wang, X. Hu, F. Sun, and D. G. Dorrell, "A comparative study of equivalent circuit models of ultracapacitors for electric vehicles," Journal of Power Sources, vol. 274, pp. 899906, 2015.

[6] S. Stefan, Power Sources for Hybrid Electric Vehicles. [M. thesis], Lund University, Faculty of Engineering, USA, 2009.

[7] A. B. Cultura and Z. M. Salameh, "Modeling, evaluation and simulation of a supercapacitor module for energy storage application," in Proceedings of the International Conference on Computer Information Systems and Industrial Application, pp. 876-882, 2015.

[8] L. Zhang, W. Zhenpo, F. Sun, and D. Dorrell, "Ultracapacitor modelling and parameter identification using the extended kalman filter," ITEC Asia Pacific, vol. 7, pp. 3204-3217, 2014.

[9] L. Shi and M. L. Crow, "Comparison of ultracapacitor electric circuit models," in Proceedings of the IEEE Power and Energy Society 2008 General Meeting: Conversion and Delivery of Electrical Energy in the 21st Century, PES, Pittsburgh, PA, USA, July 2008.

[10] S. Ban, J. Zhang, L. Zhang, K. Tsay, D. Song, and X. Zou, "Charging and discharging electrochemical supercapacitors in the presence of both parallel leakage process and electrochemical decomposition of solvent," Electrochimica Acta, vol. 90, pp. 542-549, 2013.

[11] L.-Q. Jin, Y. Zheng, J.-H. Li, and Y.-L. Liu, "A study of novel regenerative braking system based on supercapacitor for electric vehicle driven by in-wheel motors," Advances in Mechanical Engineering, vol. 7, no. 3, pp. 1-12, 2015.

[12] S. Hala, N. Khalil Faris, and N. Khaled Faris, "Ultracapacitor: modelling and characterization for electric vehicle application," International Journal of Engineering Research, vol. 5, pp. 681686, 2015.

[13] S. Fletcher, L. Kirkpatrick, R. Drink, R. Puttock, R. Thring, and S. Howroyd, "The modelling of carbon-based supercapacitors: distributions of time constants and pascal equivalent circuits," Journal of Power Systems, vol. 345, pp. 247-253, 2017.

[14] Y. Fuyuan, L. Languang, Y. Yuping, and Y. He, "Characterization, analysis and modeling of an ultracapacitor," World Electric Vehicle Journal, vol. 4, pp. 358-369, 2010.

[15] L. Zhang, Z. Wang, F. Sun, and D. G. Dorrell, “Online parameter identification of ultracapacitor models using the extended Kalman filter," Energies, vol. 7, no. 5, pp. 3204-3217, 2014.

[16] G. L. Plett, "Extended Kalman filtering for battery management systems of LiPB-based HEV battery packs-part 1. Background," Journal of Power Sources, vol. 134, no. 2, pp. 252-261, 2004.

[17] M. Michalczuk, M. Grzesiak Lech, and B. Ufnalski, "A lithium battery and ultracapacitor hybrid energy source for an urban electric vehicle," Politechnika Warszawska, vol. 4, pp. 158-162, 2012.

[18] M. Ashar, "Integration of ultra capacitor with battery using DCDC bidirectional buck boost converter in an electric vehicle," International Research Journal of Engineering and Technology, vol. 3, pp. 1513-1517, 2016.

[19] M. Bottu, M. L. Crow, A. C. Elmore, and S. Atcitty, "A Power electronic conditioner using ultracapacitors to improve wind turbine power quality," Smart Grid and Renewable Energy, vol. 4, pp. 69-75, 2013. 


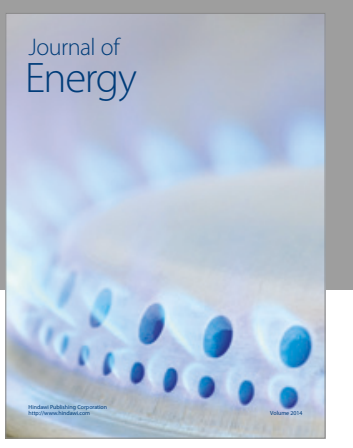

Journal of

Industrial Engineering
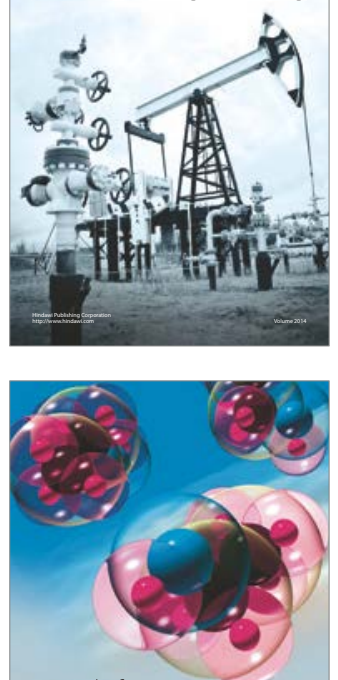

Fuels
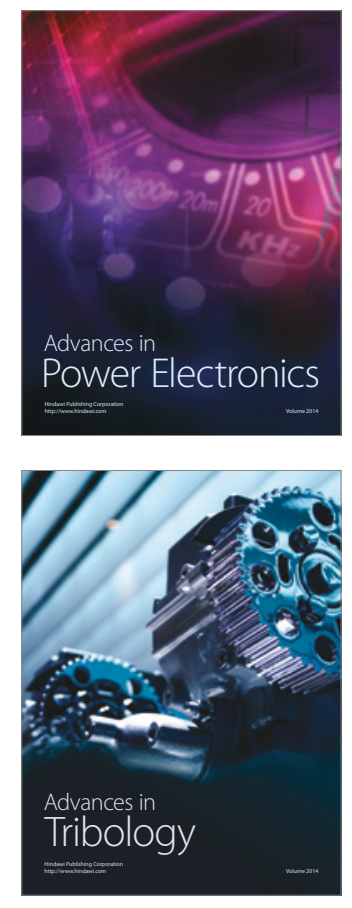
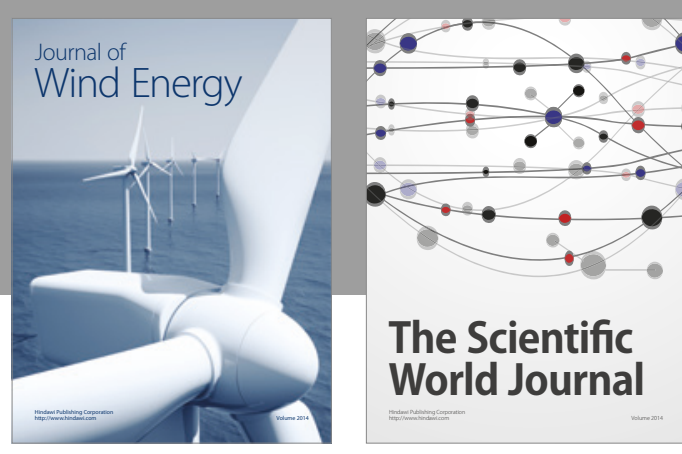

The Scientific World Journal
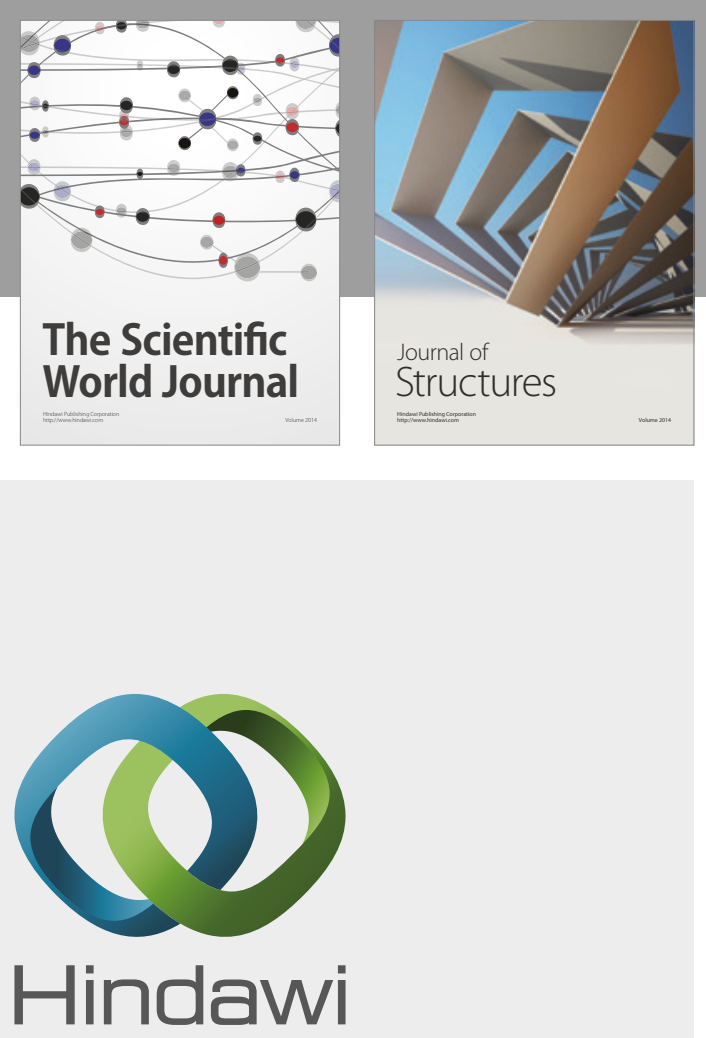

Submit your manuscripts at

https://www.hindawi.com
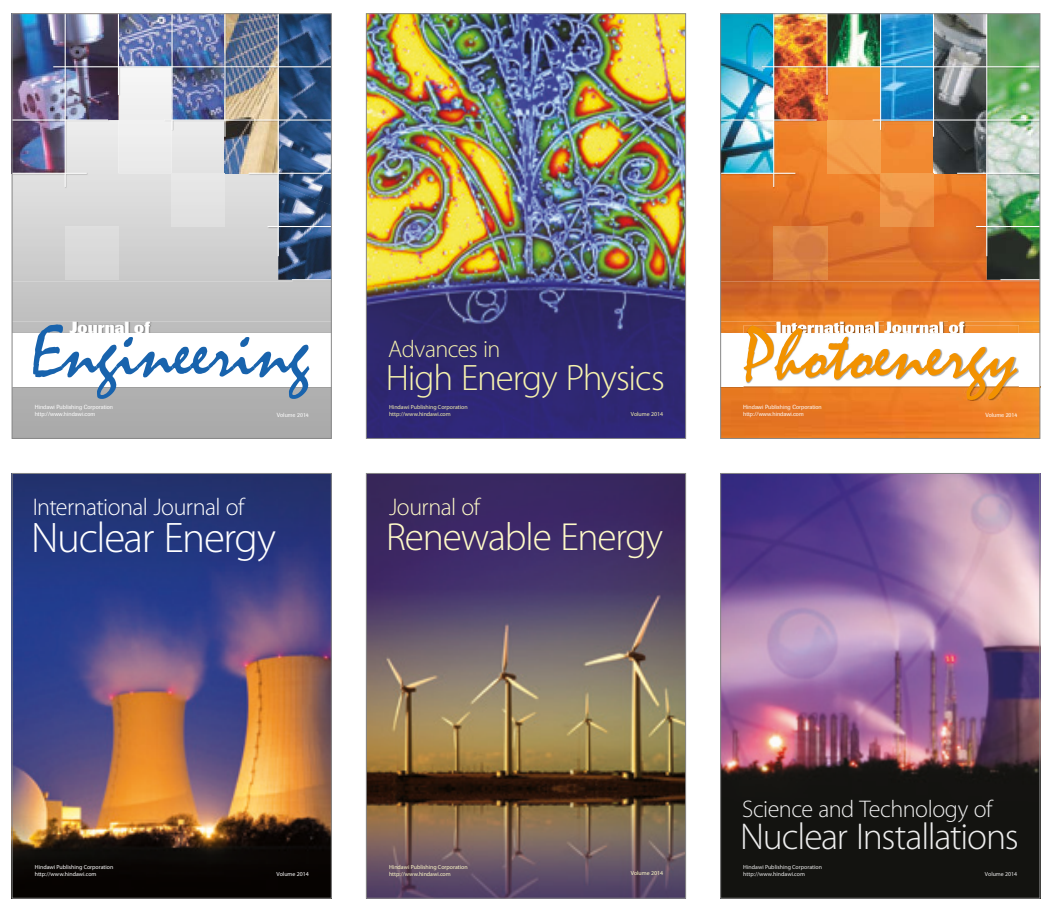

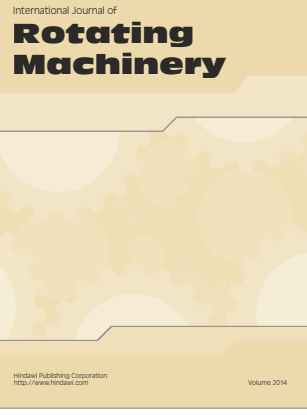

Journal of

Petroleum Engineering

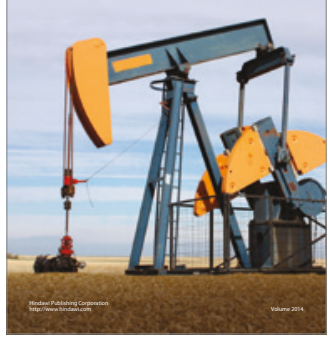

Journal of
Solar Energy
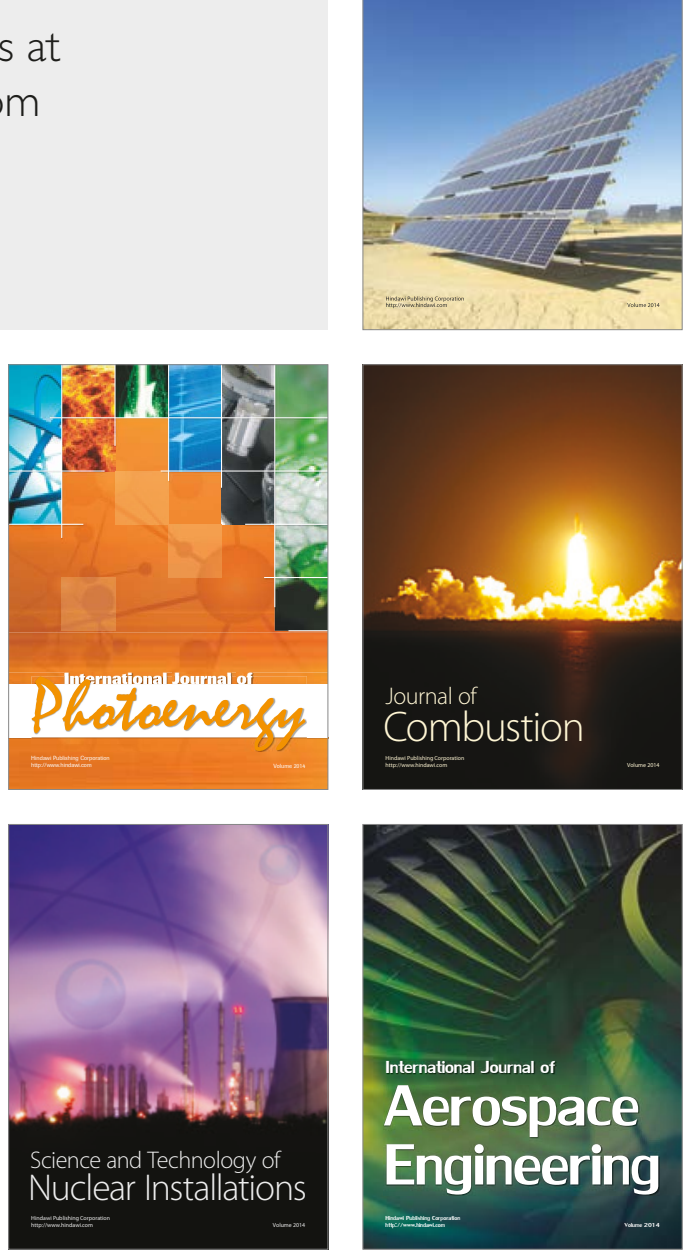